\title{
A list of historical comets observed at plural sites: the beginning of astronomy in Japan and Korea
}

\author{
Kiyotaka Tanikawa and Mitsuru Sôma \\ National Astronomical Observatory of Japan \\ 2-21-1 Osawa, Mitaka, Tokyo, 181-8588, Japan \\ email: tanikawa.ky@nao.ac.jp, Mitsuru.Soma@nao.ac.jp
}

\begin{abstract}
Comets generally stay long in the sky and can be seen from many places on the surface of the Earth. We are interested in historical comets which were observed at plural sites. We have shown in a previous work (Tanikawa \& Sôma, 2008) that in the seventh century, five comets were observed independently in China and Japan. From this fact and other data, we deduced that Japanese observational astronomy started in the seventh century. We know that, other than China and Japan, Korea and Vietnam had observational astronomy before the 9th century. We look for historical comets observed at plural sites by surveying the existing literature of respective countries. Examining the independence of the records, we provide a list of comets observed independently at plural sites. This strengthens the reliability of the records of comets. The list can be used for other purposes.
\end{abstract}

Keywords. Japanese and Korean astronomy, seventh century, plural observations

\section{Introduction}

The astronomy until the end of the 17th century was the kinematics of bodies in the Solar System. More concretely, main contents of astronomy were (1) motion of the Sun; (2) motion of the Moon; (3) motion of five planets among constellations; (4) maintenance of constellations as a coordinate system on the celestial sphere. Dynamics has been incorporated since 1687 when I. Newton published Principia. The Solar System was the unique world until 1838 when the parallax of stars was measured.

Careful astronomers observed the sky day and night. They noticed unusual phenomena in the sky. Among them were gueststars (novae) and comets. These objects stayed long in the sky, so some of them were observed in plural civilized countries. We present a list of these comets until the end of the eighth century. Chinese and Korean Data have been taken from the list compiled by Hasegawa (1979). Vietnamese data are from Ho Peng-Yoke (1964). We divide Korean data into those of three kingdoms.

The beginning of observational astronomy in the east Asian countries, in particular, in Japan and Korea are interesting. The main relevant data are solar eclipses, lunar eclipses, and occultations of planets by the moon. These are useful since the existence of these phenomena can be checked by modern calculations. In this sense, comet records are auxiliary. However, records of comets observed in different places are important because the reliability becomes high. We have shown that Japanese observational astronomy began in the 7th century using solar and lunar eclipses, occultations, and five common comets with China and/or Korea. We tried to show the beginning year of the astronomy in the three kingdoms of Korea. We have not been successful. We guess that the data were lost. 


\section{A list of comets observed at Plural sites until the eighth century}

Ho Peng-Yoke admits that earlier Vietnamese data are taken from Chinese sources. Some of Korean data of three Kingdoms may have been also taken from Chinese sources.

\begin{tabular}{|c|c|c|c|c|c|c|c|}
\hline \multirow{2}{*}{$\begin{array}{r}\text { No. } \\
12\end{array}$} & \multicolumn{2}{|c|}{ Date of discovery } & Country & \multirow{2}{*}{$\begin{array}{l}\text { No. } \\
245\end{array}$} & \multicolumn{2}{|c|}{ Date of discovery } & \multirow{2}{*}{$\begin{array}{l}\text { Country } \\
\text { China, Baekje }\end{array}$} \\
\hline & -1495 & & Syria, Chaldea, India(?) & & 302 & May-June & \\
\hline 59 & -203 & Aug.-Sept & China, Vietnam, Europe & 249 & 305 & Nov. 21 & China, Rome \\
\hline 74 & -156 & Oct. & China, Vietnam & 253 & 336 & Feb. 16 & China, Baekje, Rome \\
\hline 75 & -154 & Winter & China, Vietnam & 259 & 363 & Aug.-Sept. & China, Rome \\
\hline 77 & -153 & Feb. & China, Vietnam & 266 & 383 & Oct.-Nov. & Goguryeo, Europe \\
\hline 78 & -147 & May & China, Vietnam & 270 & 390 & Aug. 7 & China, Baekje, Rome \\
\hline 80 & -146 & Aug.6 & China, Syria & 275 & 400 & Mar. 19 & China, Baekje, Rome \\
\hline 81 & -146 & Nov. & China, Vietnam & 284 & 415 & June 24 & China, Baekje \\
\hline 84 & -137 & Aug. & China, Vietnam & 287 & 418 & June 24 & China, Europe \\
\hline 90 & -134 & Sept. & China, Vietnam & 288 & 418 & Sept. 15 & China, Europe \\
\hline \multirow[t]{2}{*}{95} & -118 & May & China, Vietnam, & 289 & 419 & Feb. 17 & China, Baekje \\
\hline & & & Asia Minor & 291 & 421 & Jan.-Feb. & China, Europe \\
\hline 107 & -86 & Aug. & China, Rome & 292 & 422 & Mar. 26 & China, Europe \\
\hline 119 & -48 & Apr. & China, Silla & 301 & 442 & Nov. 10 & China, Europe \\
\hline 122 & -43 & May-June & China, Silla & 305 & 451 & June-July & China, Rome \\
\hline 127 & -31 & Feb. & China, Greece & 307 & 453 & Feb.-Mar. & China, Rome? \\
\hline 132 & -11 & Aug. 26 & China, Rome & 315 & 467 & Feb. 6 & China, Europe \\
\hline 135 & -3 & Apr. & China, Silla & 319 & 498 & Dec. & China, Europe \\
\hline 144 & 54 & June 9 & China, Silla, Europe & 326 & 530 & Aug. 29 & China, Rome \\
\hline 146 & 60 & Aug. 9 & China, Silla?, Rome & 333 & 539 & Nov. 17 & China, Europe \\
\hline 147 & 61 & Sept. 27 & China, Rome & 334 & 541 & Feb.-Mar. & China, France \\
\hline 148 & 64 & May 3 & China, Rome & 354 & 582 & Jan. 15 & China, France \\
\hline 157 & 76 & Oct. 7 & China, Rome & 361 & 595 & Jan. 9 & China, Baekje, Europe \\
\hline 159 & 79 & Oct. 7 & Silla, Rome & 376 & 626 & Mar. 26 & China, Europe \\
\hline 161 & 85 & June 1 & China, Baekje, Silla & 379 & 634 & Aug.-Sept. & China, Japan \\
\hline 171 & 128 & Sept.-Oct. & Silla, Asia Minor & 381 & 639 & Mar. 5 & Baekje, Japan \\
\hline 178 & 149 & Oct. 19 & China, Silla & 392 & 668 & May-June & China, Goguryeo \\
\hline 181 & 158 & Mar.-Apr. & Goguryeo, Europe & 396 & 676 & Sept. 4 & China, Silla, Japan, \\
\hline 182 & 161 & June 14 & China, Rome & & & & Europe \\
\hline 185 & 182 & Aug.-Sept. & China, Goguryeo & 398 & 681 & Oct. 17 & China, Japan \\
\hline \multirow[t]{2}{*}{191} & 191 & Oct. & China, Baekje, Silla, & 399 & 683 & Apr. 20 & China, Silla \\
\hline & & & Rome & 400 & 684 & Sept. 6 & China, Japan \\
\hline 196 & 200 & Nov. 6 & China, Silla (Error?) & 402 & 6841 & Dec. -685 Jan. & Japan, Europe \\
\hline 197 & $204 \mathrm{Dec}$ & c. -205 Jan. & China, Baekje, Rome & 412 & 712 & July-Aug. & China, Europe \\
\hline 203 & 217 & Nov.-Dec. & China, Goguryeo & 424 & 744 & Winter & Korea, Syria \\
\hline 204 & 218 & Apr.-May & China, Rome & 428 & 760 & May 16 & China, Europe \\
\hline 228 & 269 & Oct.-Nov. & China, Baekje & 435 & 770 & May 26 & China, Silla, Japan \\
\hline 243 & $300 \mathrm{Dec}$ & c. -301 Jan. & China, Goguryeo & 436 & 773 & Jan. 15 & China, Japan \\
\hline
\end{tabular}

Dates in the table are given by the Julian Calendar.

\section{References}

Ho, Peng-Yoke, 1964, J. Amer. Orient. Soc. 84, 127-149.

Ichiro, Hasegawa, 1979, Publ. Astron. Soc. Japan 31, 257-270.

Tanikawa \& Sôma, 2008, Rep. Nat. Astron. Obs. Japan 11, 31-55. 